\title{
FOAMING CHARACTERISTICS OF THE FOOD-INDUSTRY BIOLOGICAL WASTEWATER TREATMENT PLANT
}

\author{
Manyele S. $V$. \\ Department of Chemical \& Process Engineering, College of Engineering and Technology \\ University of Dar es Salaam, P.O. Box 35131, Dar es Salaam, Tanzania \\ smanyele@cpe.udsm.ac.tz
}

\begin{abstract}
Intensive foaming observed during aeration of the aerobic food industry wastewater treatment plant is presented. This study was conducted to establish the foaming characteristics using a pilot three-phase fluidized bed bioreactor (TPFBB). A fluidization column $(0.2 \mathrm{~m}$ i.d. and $6 \mathrm{~m}$ high) was used. The TPFBB was loaded with variable masses of novel biomass support particles (BSP). Wastewater samples collected from a plant processing both vegetable oil (VOPWW) and soap $(S P W W)$ were immediately introduced in the TPFBB for aeration. The characteristics studied include: variation of foam volume with time, foam multiplicity, foaming and foam collapse rates. The SPWW produced excessive foam volumes at a higher rate and higher foam multiplicity compared to VOPWW. Dilution, increasing aeration rate or BSP loading led to higher foaming rate, which decreased with time. Spraying wastewater at the top of the liquid surface minimized foaming rate.
\end{abstract}

Keywords: Food processing aspects; Vegetable protein derivatives; oils; rate of foaming; foam collapse rate; biomass support loading.

\section{INTRODUCTION}

Foaming in biological reactors constitutes a big problem as it hinders aeration for the aerobic processes and leads to material losses. Handling foam increases operating costs and reduces process performance (Stratton et al., 1998). Stable foaming in biological wastewater treatment plants have been attributed to the nature of the microorganisms present in the wastewater (Davenport and Curtis, 2002; Pagilla et al., 2002; Barjenbruch et al., 2000; de los Reyes et al., 1998; Stratton et al., 1998; Westlund et al., 1998; Holmstrom et al., 1996).

The existence of stable foam in the TPFBB seems surprising because of the high mobility of the molecules in both phases. The formation of foam in the TPFBB is accompanied by a tremendous extension of the liquid-air interface when gas is blown into a liquid through small orifices on a perforated distributor plate. Foam cannot be formed from pure liquids (Everett, 1988), but only colloidal solutions are able to foam, like industrial wastewater from food processing industries. Some surface films, particularly those of the higher fatty acid soaps, actually exhibit plastic properties due to the close packing of large molecules. Obviously, such films would produce highly stable foam, and necessitate low aeration rates of the biological wastewater treatment plants.

Foam consists of globular liquid films enclosing gas, which exist as coarse dispersions in a relatively small amount of liquid. In most foam, the gas bubbles (with sizes not in the colloid sizes range) are initially spherical but rapidly adopt a close packed-structure in which the individual bubbles are separated by a thin liquid film of colloidal thickness. The foam bubbles are covered by elastic semi-solid films (Harry, 1968), which forms lamellar structures throughout the foam with a definite layer structure (Krhutková and Wanner, 1999; Wanner, 1998; Wanner et al., 1998). The film comprises of three layers, the two outer layers consisting of soap, and the middle layer containing water. In such bubbles, molecules are oriented such that the hydrocarbon tails are turned outside, and the carboxyl groups directed towards the middle layer of water (Harry, 1968). The whole film is usually very thin, thickness of which can be estimated from the color of the bubble.

The main condition for stable foam is the formation of a lamellar framework (Hammond, 1958; Bikerman, 1953). For this purpose, large lamellar or fibrous particles, e.g., those present in soap and in the vegetable oil processing wastewater must be present. The stabilization of the film with saponin, tannins, dyes or high molecular weight compounds, e.g., proteins, leads to the formation of highly viscous and strong three-dimensional structures in the surface layer that greatly retard the thinning and rupture of the film, leading to stable foam. Addition of ethanol to the wastewater has also been reported to cause foaming and bulking (Holmstrom et al., 1996). Foaming and bulking have also been correlated to the production of volatile fatty acids during wastewater treatment (Holmstrom et al., 
1996) also to biosulfactant production (Pagilla et al., 2002). The SPWW contains washing and cleaning agents based on vegetable oils, which leads to strong foaming. Some studies have associated foaming with food-to-mass ratio (Westlund et al., 1998).

The stability of the foam depends on the persistence of the films separating the gas bubbles (Bikerman, 1953). The lifetime of foam bubbles, that is, their persistence increases with decreasing average diameter. To minimize foam, other researchers suggest use of pretreatement of the wastewater by heat (Barjenbruch et al., 2000); reduction of sludge load (Westlund et al., 1998), dosage of antifoam agents, etc., which adds up to the operational costs of the wastewater treatment plants.

In operational practices, it is more often necessary to destroy undesirable foam than to promote foam formation. Foaming can be advantageous for mass transfer but can cause serious operating problems, and therefore it has to be minimized. There are several methods in which foaming problems can be nullified.

Antifoam agents are chemical additives, in the same classes as de-foamers but may differ in particulars of composition and use, and are liquids, which are immiscible with the primary liquid and have a great spreading power, so that a relatively small quantity will form a thin, continuous coating film. Antifoam agents are composed of oils, fatty acids, esters, polyglycols and siloxanes which destabilize protein films. They do not function as foam breakers through surface activity, but through a covering action that is more nearly mechanical in nature. However, their surface properties in relation to the primary liquid are important in determining their very essential spreading ability. However, mass transfer mechanisms and biological activity in a TPFBB can be interfered by the presence of anti- foam agent, which is the drawback of applying this method in foam control.

Physical methods of de-foaming include attacking the foam mechanically, thermally or electrically. Mechanical methods include static (Yamagiwa et $a l ., 2000)$ or rotating breaker bars, rotating slinger that moves in the freeboard space, stationary bars or closely spaced plates in contact with the rising foam will help to control its level. Thermal methods involving evaporation of water vapor from thin films can play a role in foam destabilization by thinning the film to less than the critical thickness at which it collapses. However, this method is not valid in a TPFBB due to the fact that, the microorganisms are affected by thermal means and therefore wastewater treatment performance could be affected.

Automatic foam control includes automatic systems for sensing and controlling foam level, for instance in sensitive industrial process likes fermentation for the manufacture of antibiotics. In the penicillin manufacture for instance, peanut oil is used as antifoam agent. The automatic foam control equipment consist essentially of a sensing electrode that is activated by contact with the foam, a solenoid that opens to admit de-foamer to the tank, and reset timer to regulate the length (and hence the size) of addition. This method is expensive due to its complexity and is not cost effective for use in foodindustry wastewater treatment.

\section{MATERIALS AND EXPERIMENTAL FACILITIES}

The TPFBB comprise of a $0.2 \mathrm{~m}$ i.d. $\mathrm{x} 6 \mathrm{~m}$ high glass column, (as shown in Figure 1) with the distributor mounted at the bottom. The distributor comprise of gas and liquid inlets entering at its bottom. 


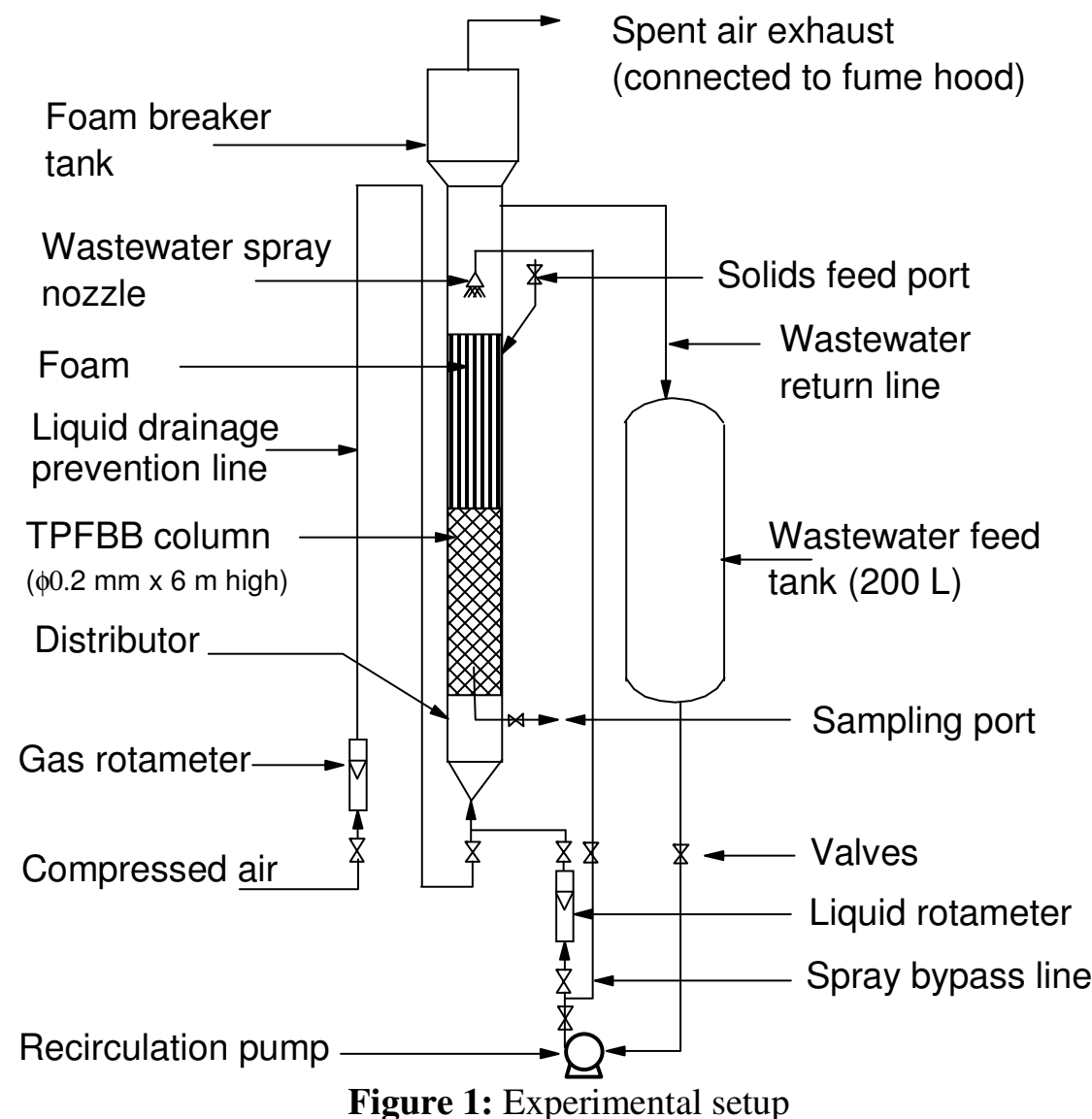

The foam breaker tank is a small tank which is mounted at the top of the TPFBB to offer space and accommodate foam, allowing the gas to separate from the liquid and foam, as well as effecting reduction of exhaust air pressure.

The biomass support particles (solid phase) comprised of the polyethylene particles, called the $\mathrm{KMT}^{\mathrm{R}}$ support, depicted in the photograph, Figure 2. A known weight $\left(M_{\mathrm{s}}\right)$ of solids was introduced into the fluidization column through the solids feed port.
Wastewater samples collected from the industry were then introduced in the feed tank of about 200 liters. The pump connected below the tank was used to feed a known volume of wastewater into the fluidization column through a liquid rotameter. Before air is introduced the solids $\left(\square=850 \mathrm{~kg} / \mathrm{m}^{3}\right.$ ) float on the surface of the liquid, shape of which is shown in Figure 2.

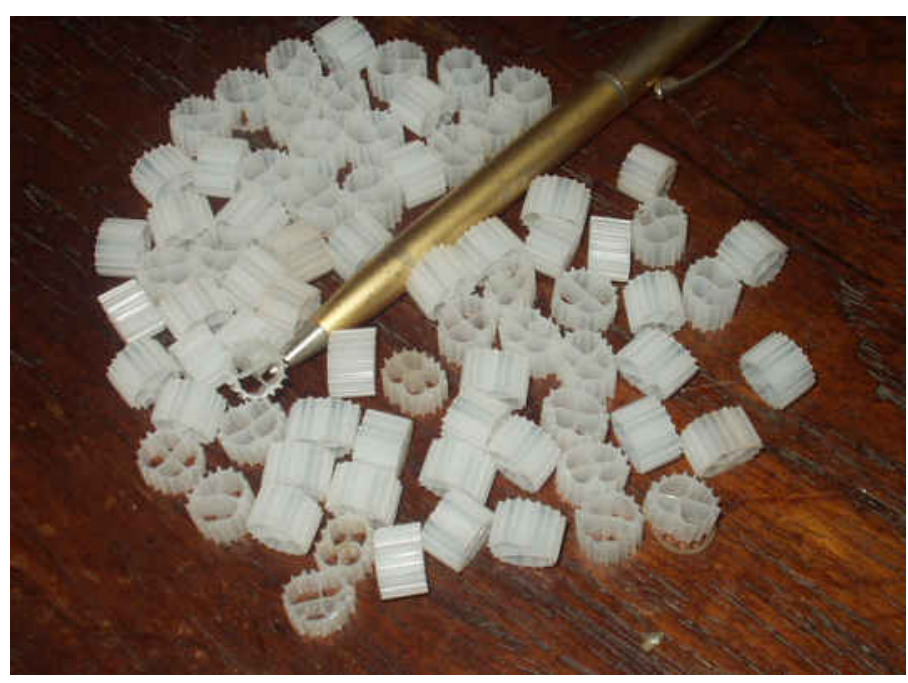

Figure 2: Photograph of the $\mathrm{KMT}^{\circledR}$ biomass support particles (BSP) 
The air enters the distributor after passing through the gas rotameter and through the liquid drainage prevention line (aimed at preventing the water from reaching the compressor during shutdown). After mixing with the liquid in the distributor wind box, the gas enters the column via a $10-\mathrm{mm}$ thick perforated plate distributor. Foam was generated as the three phases mix thoroughly inside the column (fluidization state) and collects above the surface of the liquid in the column (as shown in Figure 1). The solids remain in the suspended mode as the liquid and gas pass upwards.

The focus of this study was to investigate the characteristics of the foam collected at the top of the liquid surface. The foam accumulates above the liquid increasing in cumulative volume, obtained by reading the height of the column occupied by the foam as a function of foaming time.

The critical foam height corresponding to $0.12 \mathrm{~m}^{3}$ of foam was fixed as a maximum height beyond which ecording of heights was stopped. The BSP loading ranged from 0.5 to $3.5 \mathrm{~kg}$. In particular, three values of $M_{\mathrm{s}}$ were used, that is: $1.0,2.5$ and $3.5 \mathrm{~kg}$. The gas velocity, which ranges up to a maximum of $42 \mathrm{~mm} / \mathrm{s}$ was fixed in the lower range at three values: 7.8, 12.1 and $18.4 \mathrm{~mm} / \mathrm{s}$ only to avoid excessive foaming, which interrupts the data collection. The effect of concentration of foaming agents in the wastewater was tested by comparing the undiluted and diluted samples.

\section{MODELING OF FOAM CHARACTERISTICS}

\section{Cumulative foam volume}

The cumulative foam volume was established by recording the height of the foam in the cylindrical column, $H_{\mathrm{f}}$, with time, $t_{\mathrm{f}}$, starting from the initial liquid fluidized column height, $H_{\mathrm{c}}$. Knowing the cross-sectional area of the column, $A_{\mathrm{c}}$, the cumulative volume of the foam, $V_{\mathrm{f}}$, at a given time was established as per equation:

$$
V_{f}=A_{c}\left(H_{f}-H_{c}\right)
$$

\section{The multiplicity of foam}

The multiplicity of foam $(\beta)$ was defined as the ratio of the foam volume to the volume of the initial solution of foam-forming agent:

$$
\beta=\frac{V_{f}+V_{R}}{V_{R}}
$$

where $V_{\mathrm{R}}=$ volume of the initial solution of foamforming agent and $V_{\mathrm{f}}=$ volume of the foam $\left(\mathrm{m}^{3}\right)$.

\section{Rate of foaming}

Rate of foaming, $R_{f}$, was defined as the increase in the foam volume per unit time $\left(\mathrm{m}^{3}\right.$ foam $\left./ \mathrm{h}\right)$, expressed as per equation:

$R_{f}=\frac{\Delta V_{f}}{\Delta t}$

where $\Delta V_{\mathrm{f}}=$ increase in volume of foam due to foaming $\left(\mathrm{m}^{3}\right)$ and $\Delta t=$ change in time $(\mathrm{h})$.

\section{Rate of foam collapse}

Rate of foaming, $R_{\mathrm{c}}$, was expressed as the collapse or decrease in foam volume per unit time, expressed as per equation:

$$
R_{c}=\frac{\Delta V c}{\Delta t}
$$

where $\Delta V_{\mathrm{c}}=$ decrease in volume of foam due to collapse determined from the difference in height $\left(\mathrm{m}^{3}\right)$ and $\Delta t=$ change in time (h) corresponding to the volume change.

\section{Results and discussion}

Cumulative volume of foam

The $V_{\mathrm{f}}(t)$ curves were studied at different air velocities and BSP loading for diluted and undiluted SPWW samples, as shown in Figure 3. A critical height corresponding to $V_{\mathrm{f}}=0.12 \mathrm{~m}^{3}$ (when the foam height reaches the foam breaker tank) was fixed for all runs, above which recording of $V_{\mathrm{f}}$ was stopped. 


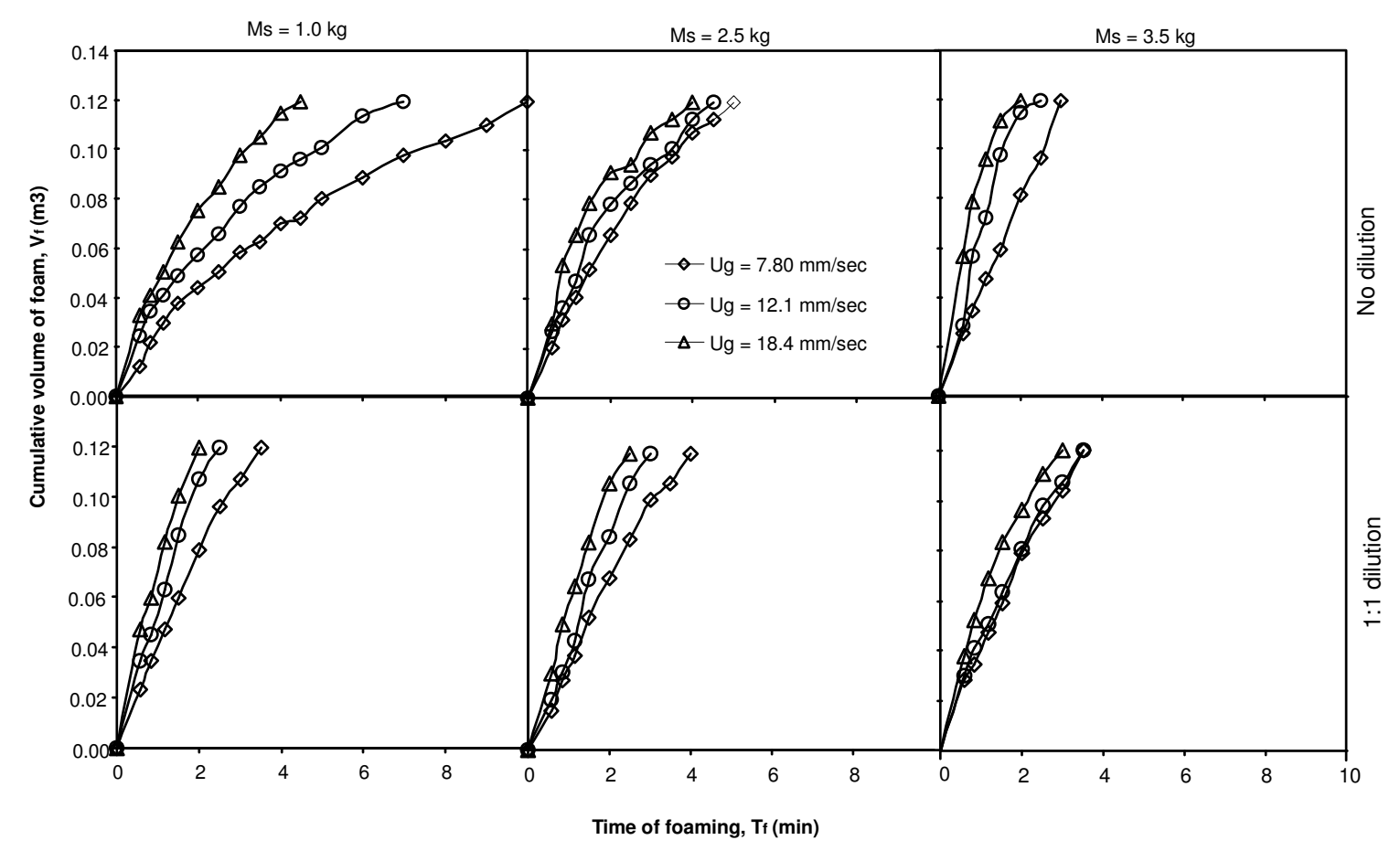

Figure 3: Variation of the volume of foam with time at different operating conditions for SPWW

For undiluted samples, increasing BSP loading increased $V_{\mathrm{f}}$ faster, reaching the critical volume earlier at $T_{\mathrm{f}}=5$ and 3 minutes for $M_{\mathrm{s}}=2.5$ and 3.5 $\mathrm{kg}$, respectively. The effect of increasing gas velocity was observed to be small except for a lowest BSP loading of $1.0 \mathrm{~kg}$, whereby longest time of 10 minutes was observed for a lower gas velocity of $7.8 \mathrm{~mm} / \mathrm{s}$. On the other hand, for diluted samples, the $V_{\mathrm{f}}$ values were higher compared to undiluted samples for which the latter increased faster for all BSP loading, reaching the critical height within 4 minutes of aeration. In general, increasing both the air flow rate and the BSP loading increases $V_{\mathrm{f}}$ for all operating conditions. For diluted SPWW samples, changing $M_{\mathrm{s}}$ did not affect $V_{\mathrm{f}}$, while higher $M_{\mathrm{s}}$ increased the values of $V_{\mathrm{f}}$ for undiluted samples. This can be attributed to the fact that high $M_{\mathrm{s}} \mathrm{s}$ leads to many small bubbles in the three phase mixture, which expands after reaching the surface of the liquid and hence more foaming than at low solids loading. However, high $M_{\mathrm{s}}$ can lead to poor oxygen transfer, so that an optimum value of $M_{\mathrm{s}}$ is required to minimize foam and yet attain high oxygen transfer.

Figure 4 shows the variation of the foam volume with time for VOPWW samples. With this type of wastewater, the foam volume increased very slowly towards a maximum before it started to decay due to foam instability. The peak value of the foam volume increases with $H_{\mathrm{sL}}$ or initial liquid volume. Compared to SPWW, the volume of the foam was negligibly small for VOPWW samples, which cannot affect the wastewater treatment operations.

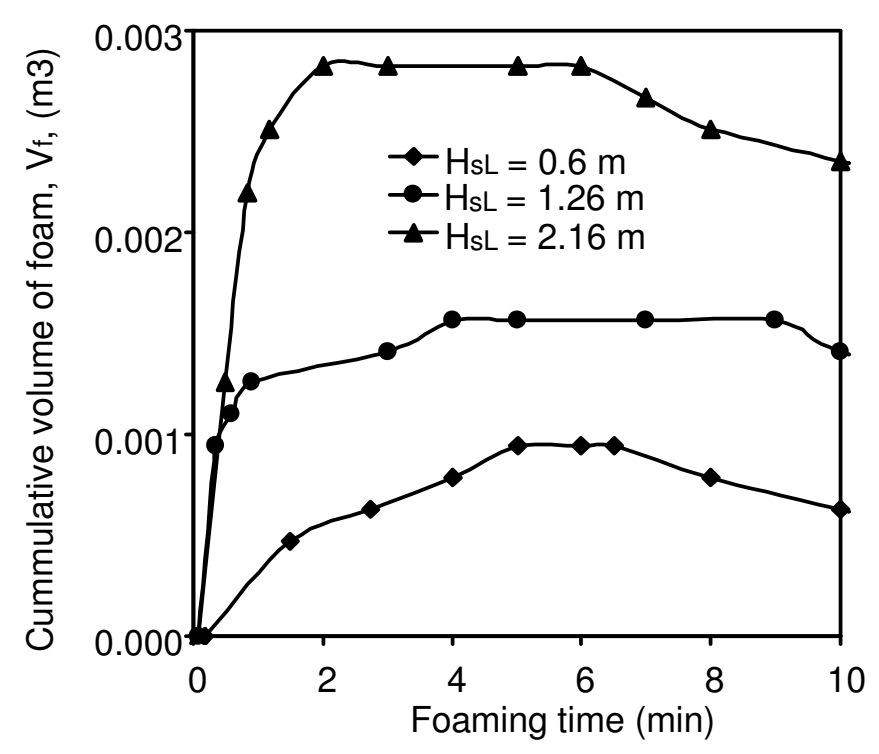

Figure 4: Variation of the volume of foam with time for VOPWW at different liquid heights $\left(U_{\mathrm{g}}=7.8 \mathrm{~mm} / \mathrm{s}\right)$

Figure 5 compares the values of $V_{\mathrm{f}}(t)$ at two BSP loading of 1.0 and $2.5 \mathrm{~kg}$ for different gas velocities. Results show that higher $M_{\mathrm{s}}$ increases $V_{\mathrm{f}}(t)$ especially at low gas velocity, while the effect of $M_{\mathrm{s}}$ is small at higher gas velocities $(18.4 \mathrm{~mm} / \mathrm{s})$. Moreover, increasing $U_{\mathrm{g}}$ increases the rate of foaming whereby the $V_{\mathrm{f}}(t)$ reached the critical value within 4 minutes at $U_{\mathrm{g}}=18.4 \mathrm{~mm} / \mathrm{s}$ compared to 10 
and 7 minutes at $U_{\mathrm{g}}=7.8$ and $12.1 \mathrm{~mm} / \mathrm{s}$, respectively, for a constant BSP loading of $1.0 \mathrm{~kg}$.

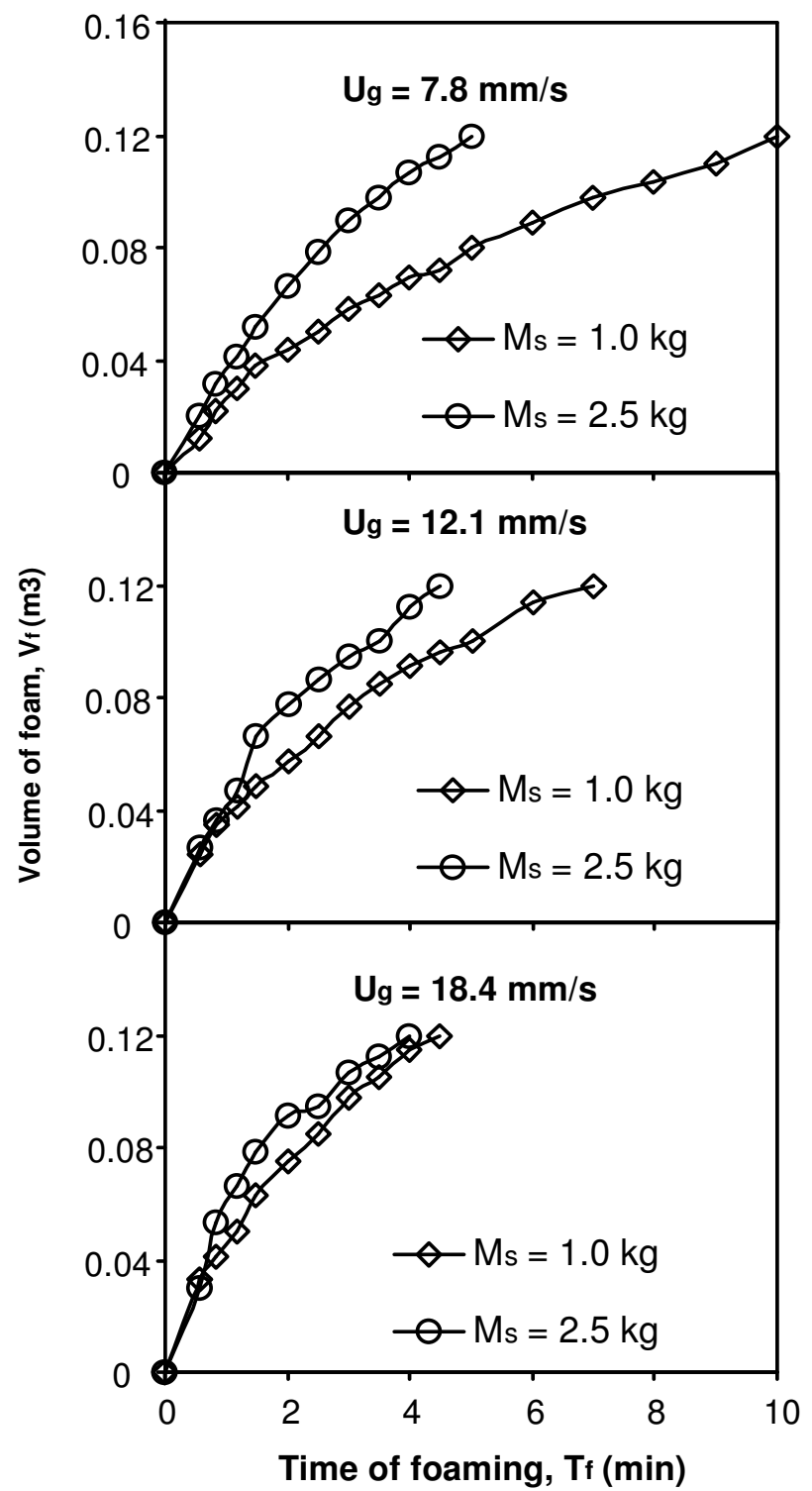

Figure 5: Effect of biomass support loading and aeration rate on the foam volume for SPWW

\section{Effect of organic loading on foaming}

In order to vary the concentrations of the wastewater samples, some of the samples were diluted. Figure 6 compares the values of $V_{\mathrm{f}}(t)$ for two levels of organic loading for the wastewater, that is, 1:1 dilution and undiluted samples as $U_{\mathrm{g}}$ was increased from 7.8 to $18.4 \mathrm{~mm} / \mathrm{s}$ at a constant BSP loading of $1.0 \mathrm{~kg}$. For the same wastewater type, there is a clear difference between diluted and undiluted samples for the values of $V_{\mathrm{f}}(t)$. While diluted samples give higher values of $V_{\mathrm{f}}(t)$ for all air velocities (reaching the critical value at 3,2 and 1.5 minutes at $U_{\mathrm{g}}$ of $7.8,12.1$ and $18.4 \mathrm{~mm} / \mathrm{s}$, respectively), undiluted samples reached the critical volume at longer times of 8,6 and 5 minutes, respectively.

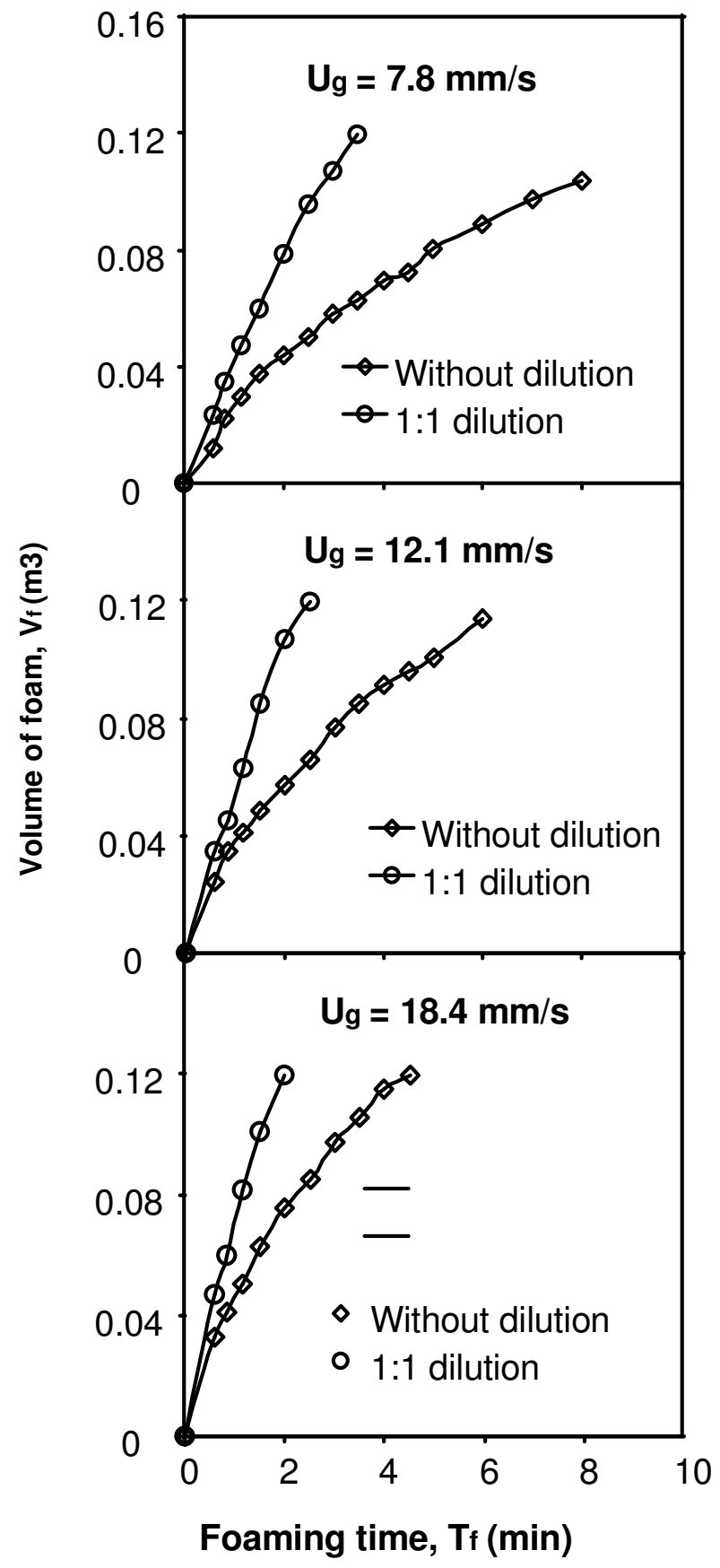

Figure 6: Effect of organic loading on the cumulative volume of foam at a constant biomass support loading $\left(M_{\mathrm{s}}=1.0 \mathrm{~kg}\right)$ for SPWW

\section{Foam multiplicity}

This quantity signifies the change in total volume of the bioreactor contents with time as a result of foaming. Figure 7 summarizes the foam multiplicity data for SPWW and VOPWW samples. For SPWW, the foam multiplicity reached a maximum of 7.3 at varying foaming tomes depending on the gas velocity. Similar curves were observed between $V_{\mathrm{f}}(t)$ and $\square t$, for all operating conditions, as shown also in Figure 3. While SPWW reached a multiplicity of 7.3 and still increasing, the VOPWW reached a maximum multiplicity within 10 minutes. 
Moreover, the multiplicity values for VOPWW were very low (1.0 to 1.15 only) compared to 1.0 to 7.3 for SPWW. Based on this observation it can be generalized that the foam generated by SPWW is more stable compared to the foam produced by VOPWW.

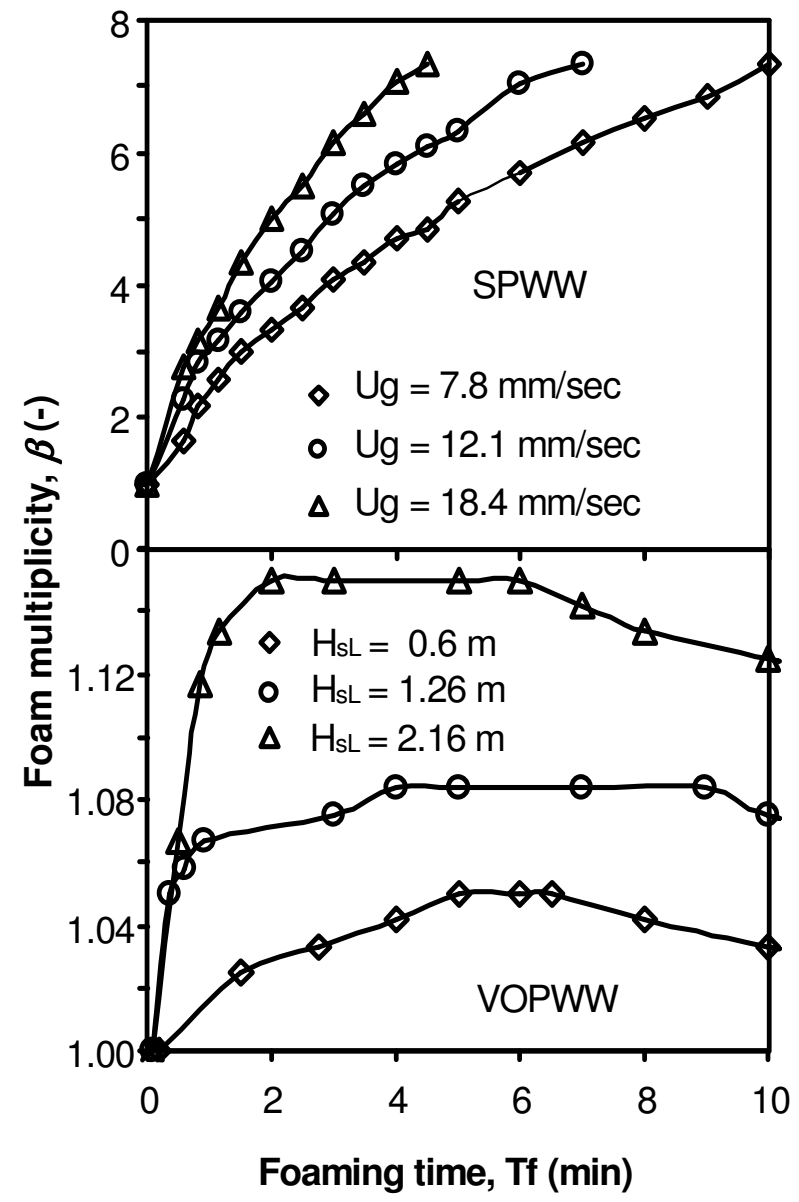

Figure 7: Values of foam multiplicity for SPWW and VOPWW samples

\section{Rate of foaming}

The rate of foaming was studied also at three different BSP loading at three air velocities for both diluted and undiluted samples. Figure 8 summarizes the results for SPWW. The rate of foaming reached up to a maximum of $7 \mathrm{~m}^{3}$ foam/h. This rate of foaming is typically an operational problem which needs attention.

For all operating conditions, the rate of foaming was observed to decrease with time. In each case, the initial rate of foaming was higher and decreased faster with aeration time. For conditions shown in Figure 8, the rate of foaming did not reach zero, indicating that the foaming was still continuing slowly. There was no observed dependency of $R_{\mathrm{f}}$ on $U_{\mathrm{g}}$. For undiluted SPWW samples, the rate of foaming increased with BSP loading for which the foaming time became shorter as $M_{\mathrm{s}}$ was increased from 1.0 to $3.5 \mathrm{~kg}$. However, for diluted samples, the foaming rate was generally higher especially at low BSP loading. Compared to undiluted samples, dilution of the SPWW samples increased the values of $R_{\mathrm{f}}$. This shows that more studies are required on the effect of organic loading on the foaming rate. 


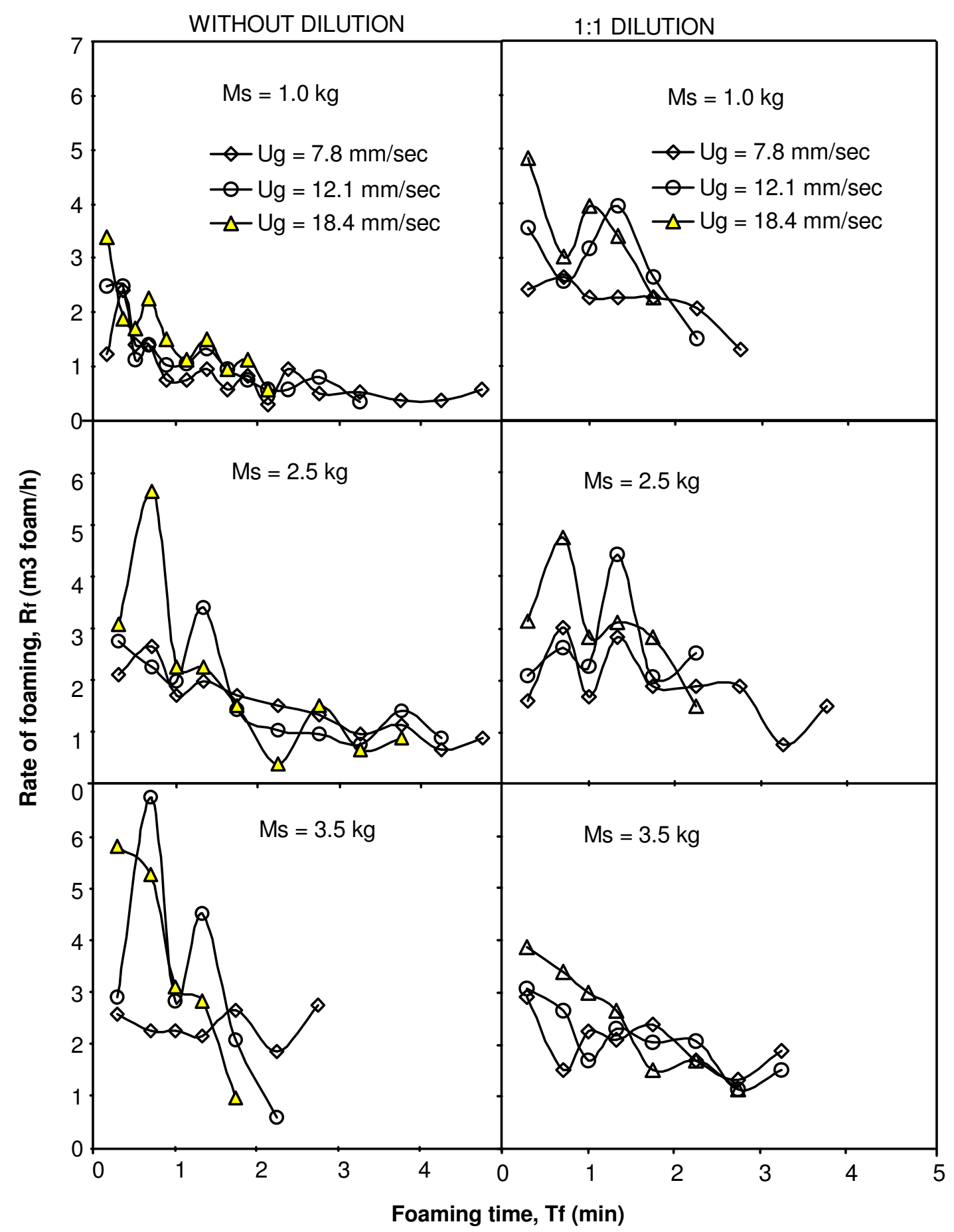

Figure 8: Variation of rate of foaming with foaming time at different operating conditions

Figure 9 shows the variation of foaming rate with foaming time for VOPWW samples. The data collected at three different $H_{\mathrm{sL}}$ values shows similar trends in which the rate of foaming was highest initially falling to zero within 5 minutes. Compared too Figures 4 and 7, this is the time when $V_{\mathrm{f}}(t)$ and $\square t$ reach maximum values. Zero values of $R_{\mathrm{f}}$ for VOPWW samples indicates that there is no change in $V_{\mathrm{f}}(t)$, while negative values of $R_{\mathrm{f}}$ indicates that the foam starts to decay or collapse. Beyond 20 minutes (Figure 9), the foaming rate remained at zero indicating a tendency of foam persistence. 


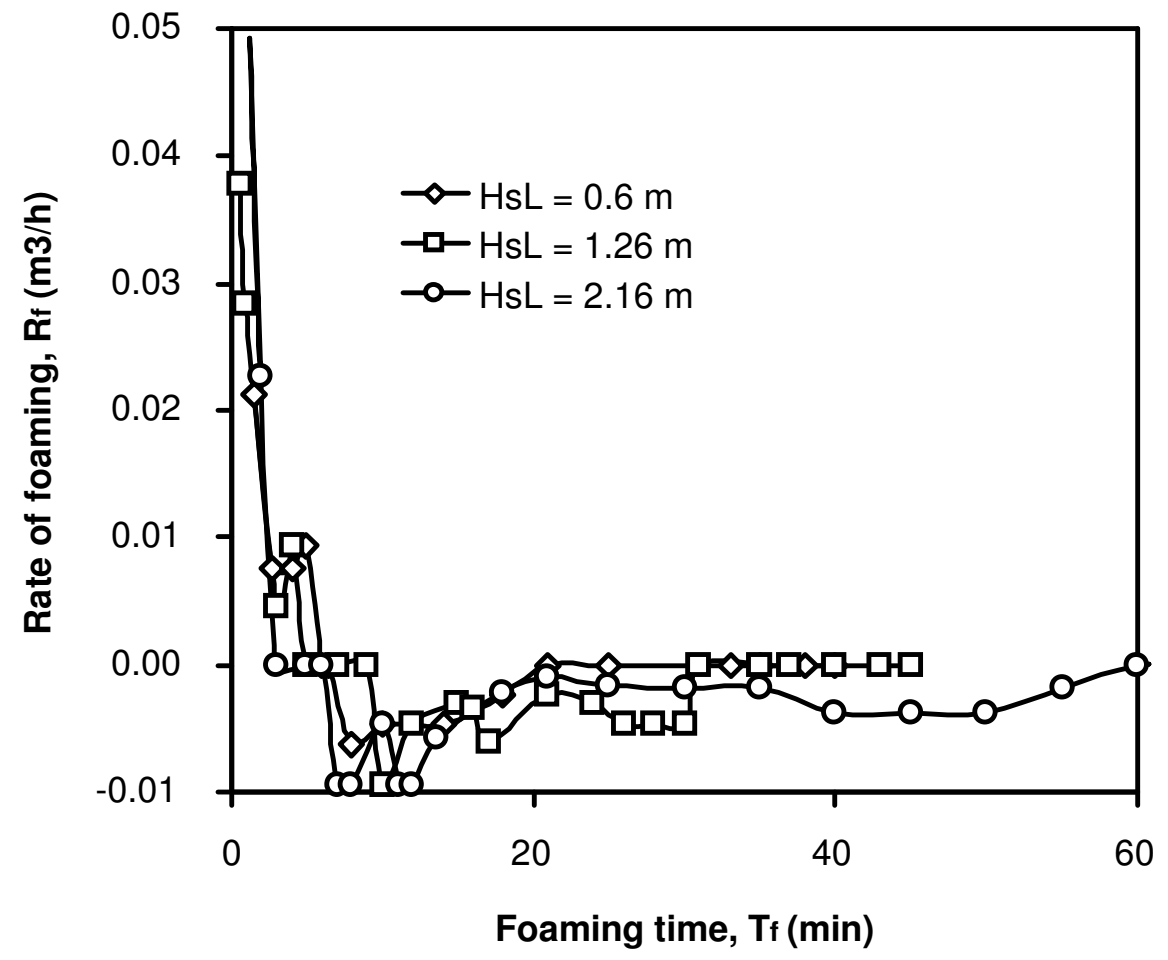

Figure 9: Variation of rate of foaming with foaming time for VOPWW at different liquid heights $\left(U_{\mathrm{g}}=7.8 \mathrm{~mm} / \mathrm{s}, M_{\mathrm{s}}=1.0 \mathrm{~kg}\right)$

\section{Foam collapse characteristics}

Foam generation is always accompanied by foam collapse at all times. However, the rate of generation is always higher than the rate of collapse during aeration, leading to excessive cumulative volume of foam in the bioreactors. Once the foam generation ceases through stoppage of aeration, the foam was observed to collapse and disappear initially faster and then slowly. In this study, the decrease in height of the foam with time was recorded for several runs giving the cumulative foam volume as shown in
Figure 10. It should b noted that, foam collapse has no operating conditions, as the foam exists at the top of the column without BSP loading and while the aeration is stopped.

The decrease in the foam volume was initially faster attributable to gravitational force acting on the trapped liquid between the foam bubbles. As the height decreases further, the height decreases slowly especially for $H_{\mathrm{f}} \leq 1.0 \mathrm{~m}$, below which the foam persists for longer time.

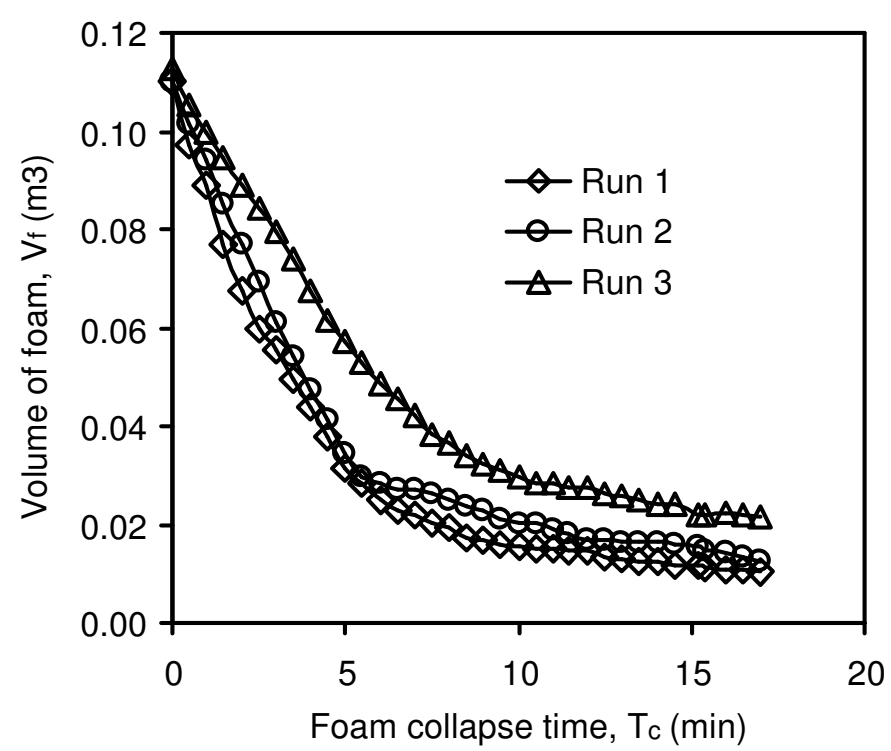

Figure 10: Variation of the foam volume with time during foam collapse test 


\section{Rate of foam collapse}

By converting the height of foam into $V_{\mathrm{f}}(t)$ using Equation (1), the rate of foam collapse, $R_{\mathrm{c}}$, was determined using Equation (3). Figure 11 shows the variation of $R_{\mathrm{c}}$ with time during foam collapse, $T_{\mathrm{c}}$. The data presents the values of rate of foam collapse determined from several runs. Initially, the rate of foam collapse is high and decreases slowly towards zero beyond 10 minutes. Compared with the rate of foaming, the rate of foam collapse is very low, indicating that once formed, the foam will exist for longer periods of time before it disappears completely.

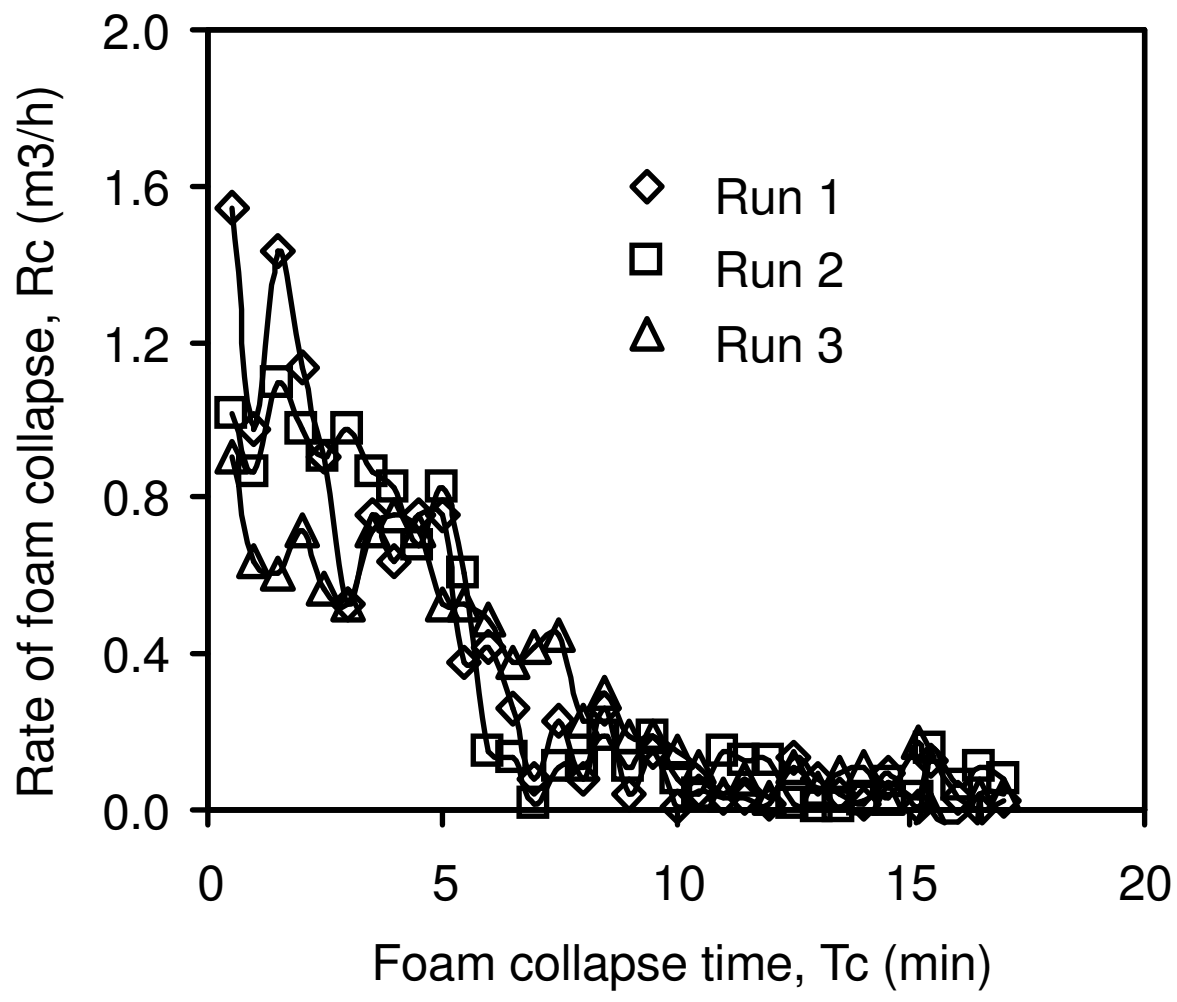

Figure 11: Variation of the average rate of foam collapse with time

Similar to the rate of foaming, the rate of foam collapse decreases to zero, showing that beyond 10 minutes, the collapse of foam ceases signifying longer persistence times. The rate of foam collapse follows the same trend for different runs indicating that only one factor controls the process of foam collapse, that is, gravitational forces.

\section{Experimental foam control}

This was studied by spraying the bypassed wastewater stream from the recirculation pump counter-currently on top of the foam, hence destroying the foam from above. This has a tendency of reducing foaming rate. The experiments were conducted at $U_{\mathrm{g}}=9.5 \mathrm{~mm} / \mathrm{s}$ with and without counter currently spray of the bypassed SPWW stream at the top of liquid and foam surface. As shown in Figure 12, the volume of foam increase with time despite the spray, indicating that $R_{\mathrm{f}}$ is higher than $R_{\mathrm{c}}$ during aeration even when a spray is applied. For the same $U_{\mathrm{g}}$ and $T_{\mathrm{f}}$ values lower $V_{\mathrm{f}}$ values were observed when a spray is applied. Thus, spraying of wastewater on top of the foam increases the foam collapse rate. 


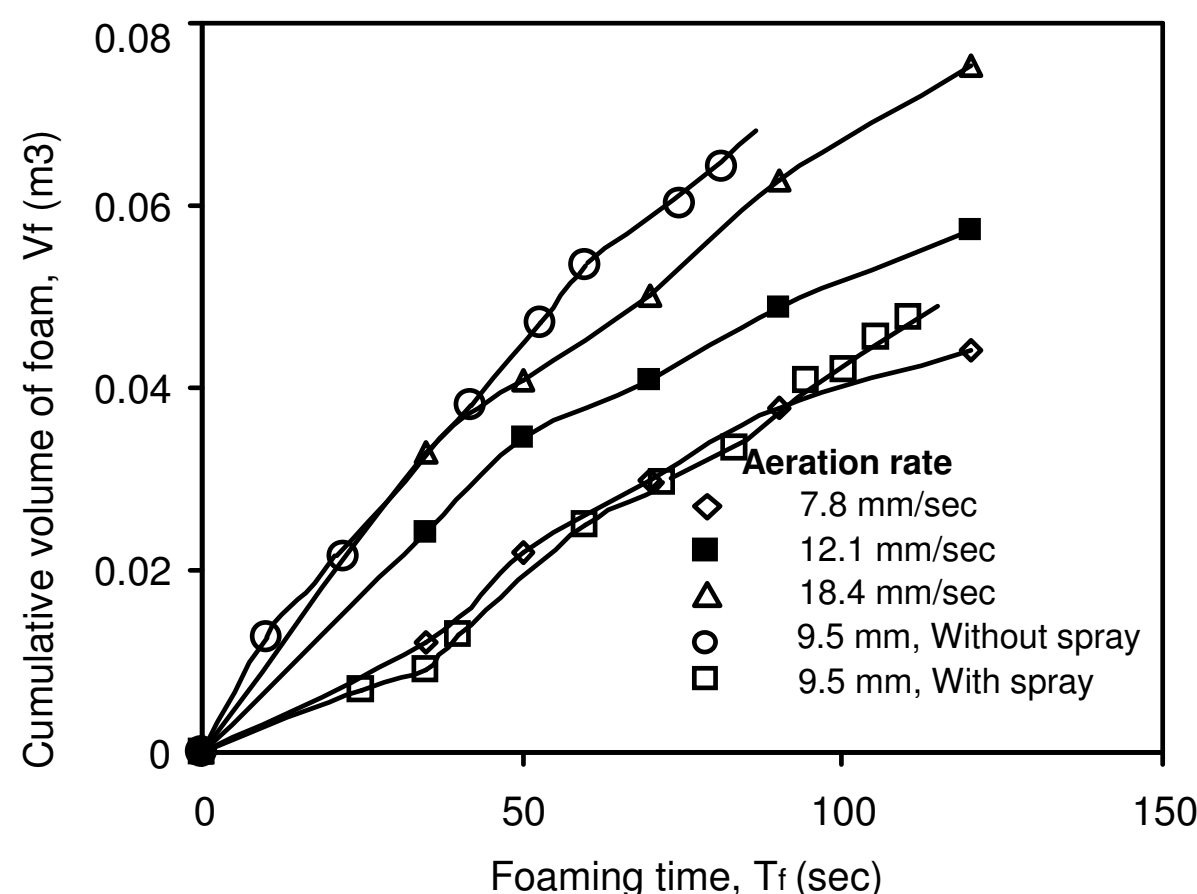

Figure 12: Effect of water spray on foam formation in the column

Spraying wastewater on top of the foam has two effects: large liquid droplets which penetrate and destroy the foam causing immediate collapse, and small droplets trapped between the bubbleinterfaces causing slow foam collapse.

\section{CONCLUSIONS}

The SPWW samples excessively produced foam, while the VOPWW samples produced small amount of foam. The main reason for this observation is the presence of (surface active agents) hydrophobic and hydrophilic substances in the SPWW samples, since the thin liquid films are stabilized by soap like materials. The rate of foaming of the soap processing wastewater using vegetable oil is critically high and can affect the performance of the TPFBB during wastewater treatment. Dilution of samples leads to higher $V_{\mathrm{f}}(t)$ values, reaching a critical value faster than undiluted samples. At higher aeration rates, however, the effect of dilution becomes minimal.

Increasing aeration rate increases the rate of foaming in biological reactors due to the increase of the fraction of air inside the bed. The effect of $U_{g}$ is stronger at low BSP loading for undiluted samples. The critical foaming times were shorter at higher $U_{\mathrm{g}}$ (3 minutes) than at low $U_{\mathrm{g}}$ ( 7 to 10 minutes). The BSP loading values of $1.0,2.5$ and $3.5 \mathrm{~kg}$ were tested in this study. Increasing $M_{\mathrm{s}}$ increased the values of $V_{\mathrm{f}}(t)$ reaching the critical value in shorter times. Moreover, the effect of $M_{\mathrm{s}}$ was observed to be stronger at low $U_{\mathrm{g}}$ only.
The rate of foaming reached a maximum of $7 \mathrm{~m}^{3} / \mathrm{h}$ of foam. The rate of foaming decreases with time for all operating conditions. This is because the foam forming components diminishes in the wastewater. Dilution of the wastewater increases $R_{\mathrm{f}}$ at low $M_{\mathrm{s}}$ but similar values were observed at higher $M_{\mathrm{s}}$. Meanwhile, foam at higher height is difficult to aerate and is strongly affected by high gravitational force in which entrapped liquid droplets have higher potential energy.

Foam collapse rate decreases with time leading to foam persistence. Initially, $V_{\mathrm{f}}(t)$ decreases faster after stopping aeration and then decreases very slowly. In general, foam generation is faster compared to foam collapse. In addition, the rate of foam collapse is highest at higher heights and lowest at the lower heights of the bed due to gravitational influence. The rate of foaming is higher than the rate of foam collapse, by about 10 times, and the collapse takes excessively long times.

Thus, once the foam is generated, it must be destroyed mechanically for optimal operation of the bioreactor. Experimental foam control was studied by spraying a bypassed wastewater stream at the top of the foam which minimizes foam formation. The spraying breaks thin wastewater films present in the foam. Further studies are required on mechanical foam control or foam minimization. 


\section{ACKNOWLEDGEMENT}

The author is grateful to Mr. Baker Francis for his contribution during data collection phase.

\section{REFERENCES}

Barjenbruch, M., Hoffmann, H., Kopplow O., and Tränckner, J., (2000), "Minimizing of Foaming in Digesters by Pre-treatment of the Surplus-sludge", Water Science \& Technology, 42(9), 235-241.

Bikerman, J.J., (1953), "Foam" Reinhold Publications Corp., New York, pp. 169.

Davenport, R.J., and Curtis, T.P., (2002), "Are Filamentous mycolata important in Foaming?" Water Science \& Technology, 46(1-2), 529-533.

de los Reyes, F.L., Oerther, D.B., de los Reyes, F., Hernandez, M., and Raskin, L., (1998), "Characterization of filamentous foaming in activated sludge systems using oligonucleotide hybridization probes and antibody probes", Water Science \& Technology, 37(4-5), 485-493.

Everett, D.H., (1998), "Basic Principles of Colloid Science", Royal society chemistry, pp 177179.

Hammond, M.R., (1958), "Dispersion of materials", Heywood and Co., London, pp 122-143.

Harry, B.W., (1968), "A Textbook of Colloid Chemistry", Second edition, John Willey, pp 350-358.

Stratton, H., Seviour, B., and Brooks, P., (1998), "Activated Sludge Foaming: What causes Hydrophobicity and can it be manipulated to Control Foaming?" Water Science \& Technology, 37(4-5), 503-509.

Holmström, H., Bosander, J., Dahlberg, A-G., Westlund, Å.D., Flyborg, L., and Jokinen, K., (1996), "Severe Bulking and Foaming at the Himmerfjärden WWTP", Water Science \& Technology, 33(12), 127-135.
Krhutková, O., and Wanner, J., (1999), "Changes in Biocenossis of Activated Sludges and Occurrence of Filamentous Microorganisms in Czech WWTPs in year 1998", In: Proceedings Design, Operation and Economics of Large Wastewater Treatment Plants, 6-9 September 1999, Budapest, Hungary.

Manyele, S.V., (1996), "Investigation of Oxygen Transfer in TPFBB in Industrial Wastewater Treatment using Novel Biomass", M.Sc. Thesis, University of Dar es Salaam, pp. 90 98.

Pagilla, K.R., Sood A., and Kim, H., (2002), "Gordonia (nocardia) amarae foaming due to biosurfactant production", Water Science \& Technology, 46(1-2), 519-524.

Wanner, J., (1998), "Stable Foams and Sludge Bulking: The Largest Remaining Problems", Journal of Inst. Water and Environ. Management, 12(5): 368-374.

Wanner, J., Ruzicková, I., Jetmarová P., Krhutková O., and Paraniaková J., (1998), “A National Survey of Activated Sludge Separation Problems in the Czech Republic: Filaments, Floc Characteristics and Activated Sludge Metabolic Properties" Water Science \& Technology, 37 (4-5), 271-279.

Westlund, Å.D., Hagland, E., and Rothman, M., (1996), "Bulking and foaming caused by microthrix parvicella at three large sewage treatment plants in the greater Stockholm area”, Water Science \& Technology, 34(5-6), 281-287.

Westlund, Å.D., Hagland, E., and Rothman, M., (1998), "Operational aspects on foaming in digesters caused by microthrix parvicella", Water Science \& Technology, 38(8-9), 29-34.

Yamagiwa, K., Yoshida, M., Ohkawa, A., and Takesono, S., (2000), "Biological treatment of highly foaming pharmaceutical wastewater by modified bubble-column under mechanical foam control", Water Science \& Technology, 42(3-4), 331-337. 